\title{
Discussion
}

\section{Isolated Congenital Absence of the Nasal Bones and Aesthetic Surgical Correction}

The authors describe a rare congenital anomaly in which the patient exhibited complete nasal bone aplasia, but no other congenital anomalies. They performed a rhinoplasty for the patient without needing to reconstruct the nasal bones, yet the result was aesthetically very acceptable.

As the authors noted, very few cases of isolated nasal bone aplasia have been reported. To give credit where it is due, it should be mentioned that Kruk et al. [3] may have been one of the first to report this anomaly in 1979. Another group of nasal bone aplasia patients was reported [1], who appeared to have an autosomal dominant trait, similar to that described by Klinger et al. They recommended no surgical treatment unless there was nasal obstruction caused by a septal deviation.

Whereas the postoperative photos show a very satisfactory visual result in the reported case, I would not be surprised if other patients with the described condition would want the nasal bone region to feel solid instead of soft, flaccid, and distensible, as demonstrated when the reported patient pinched her nostrils and blew her nose.

I confess that I would have been tempted to suggest to the patient that the nasal bone region should be reconstructed. The situation in which a plastic surgeon must reconstruct isolated nasal bone defects is seen occasionally after osteotomies in which the nasal bones have completely collapsed, resulting in an extremely narrow upper one-third of the nose. In such a circumstance, it is extraordinarily difficult to maintain the nasal bone in the desired position. The treatment in such a case that works well is onlay cartilaginous grafting.

The difficulty in considering reconstruction of the nasal bone region in cases such as that reported is that individual grafts to each nasal bone would have little to which they can be attached. However, one possible solution is a variation of the splay graft described by Guyuron et al. [2] and others [4,5] that is used occasionally to reconstruct the middle one-third of the nose. A thin piece of rib cartilage could straddle the bony septum of a patient with nasal aplasia. The issue is moot for the reported patient, however, because she was apparently content not to have the nasal bone region corrected, and the authors achieved a very fine result in every other aspect. We are grateful to them for sharing their unusual experience with us.

Ronald P. Gruber, M.D.

Departments of Plastic and Reconstructive Surgery

Stanford University

University of California, San Francisco

3318 Elm Street

Oakland, CA 94609

email: rgrubermd@hotmail.com

\section{References}

1. Ernst M, Schilbach U: Hypoaplasia of the nasal bones: An autosomal dominant inherited anomaly. HNO 35:478-481, 1987

2. Guyuron B, Michelow BJ, Englebardt C: Upper lateral splay graft. Plast Reconstr Surg 102:2169-2177, 1998

3. Kruk J, Jeske J, Koziorowska B: Congenital nasal aplasia. Pediatria Polska 54:533-535, 1979

4. Madison CJ, Cook TA: The "butterfly" graft in functional secondary rhinoplasty. Laryngoscope 112:19171925,2002

5. Stucker FJ, Lian T, Karen M: Management of the keel nose and associated valve collapses. Arch Otolaryngol Head Neck Surg 128:842-846, 2002 